\title{
A OPOSIÇÃO SILÊNCIO E INTERDITO NO FUNCIONAMENTO DA LINGUAGEM E SUAS RELAÇÕES COM A IDEOLOGIA
}

\begin{abstract}
Noeli Tejera Lisbôa
RESUMO: Ce travail se propose à identifier les différences entre silence et interdiction dans le foncionnement du discours, tout en mettant en relation le premier des deux avec un espace éminnement révolutionnaire, où il y a la possibilité de transgression du langage, et le second étant mis en relation directe à quelque forme d'interdiction, soit dans une formation discursive de domination ou de résistence. Tout en s'appuyant sur la pensée de Eni Orlandi dans Les formes du silence, le corpus de cette étude c'est l'oeuvre de l'écrivain Clarice Lispector, à partir de la compréhension de qu'il s'agit là d'un espace privilégié pour l'analyse du silence en tant que réel du discours. Finalement, ce travail présente aussi des approches significatives entre la conception de langage de Clarice Lispector, telle comme c'est possible de le percevoir dans son écriture, et la théorie de l'Analyse du Discours.
\end{abstract}

PALAVRAS-CHAVE: silêncio, interdito, real, ideologia, pontuação.

Quando a música Fado Tropical, composta por Chico Buarque e Ruy Guerra para a peça Calabar, da autoria de Chico, passou a ser tocada em todo o Brasil, em fins de 73, seus autores sequer podiam imaginar o rumo inesperado que a canção tomaria. Ao abordar, com ironia, nossa propalada herança lírica portuguesa, Fado Tropical promoveu uma inevitável analogia entre o Brasil da ditadura militar de então e a ditadura salazarista que se mantinha há 40 anos em Portugal: Mesmo quando as minhas mãos estão ocupadas em torturar, esganar, trucidar/ Meu coração fecha os olhos e sinceramente chora. A analogia, reforçada ainda por outros trechos da letra, encontra especial terreno no estribilho que, na voz da oposição brasileira, passa a simbolizar a crítica à perpetuidade da ditadura no Brasil que já alcançava seu décimo ano: Ai, esta terra ainda vai cumprir seu ideal, ainda vai tornar-se um imenso Portugal.

A música de Chico e Ruy Guerra seguia seu caminho, de oposição ao governo, já bastante familiar na obra do primeiro, quando, inesperadamente, em abril de 74, estoura a Revolução dos Cravos em Portugal que, liderada pelos capitães do exército português, depõe, pacificamente, o presidente Marcelo Caetano, pondo fim à longa ditadura no país.

O Brasil vivia, por essa época, seus primeiros momentos de distensão política, após a truculência do governo do general Garrastazu Médici. Reprimidos com violência a luta armada, os movimentos estudantis e sindicais, o início do governo do general Ernesto Geisel marca o reencontro de muitos ex-presos políticos, soltos na esteira da total desmobilização da sociedade brasileira. É nesse ambiente de renovação de esperanças e de disposição de luta, mas ainda inteiramente sob controle da repressão

Este trabalho é um fragmento da Dissertação de Mestrado A pontuação do silêncio - uma análise discursiva da escritura de Clarice Lispector, orientada pela Prof ${ }^{a}$ Dra ${ }^{a}$ Freda Indursky, no Pós-Graduação em Letras/UFRGS 
política, que a revolução portuguesa, a realidade brasileira e a letra de Chico/Ruy Guerra se encontram. Seu estribilho assume então novos sentidos, ainda na voz da oposição brasileira: do desejo de uma revolução dos cravos também para o Brasil.

Os rumos diversos dados à interpretação de Fado Tropical, num curto intervalo de tempo, mostram, de maneira exemplar, que os sentidos são móveis e que, em sua movência, rompem os limites de qualquer possível intenção de quem os produz. Isto porque, na constituição dos sentidos, historicidade e ideologia se imbricam, sendo parte essencial do funcionamento mesmo da linguagem.

No caso específico de Fado Tropical é importante observar que ambos os efeitos de sentido pertencem à mesma Formação Discursiva, ou seja, da oposição à ditadura militar que, através de um golpe, se instaurara no país desde 64. A ditadura, ou melhor dito, a crítica a esta ditadura é o interdito presente no enunciado Ai esta terra ainda vai cumprir seu ideal / ainda vai tornar-se um imenso Portugal.

Em A linguagem e seu funcionamento - As formas do discurso, Eni Orlandi (1996) diz que o silêncio tanto quanto a palavra tem suas condições de produção, o que claramente podemos observar no exemplo proposto, onde se verifica um silêncio de resistência, ou seja, um silenciamento de saberes que estão interditados pela censura imposta no país e que acabam por significar de outro modo; ao contrário, por exemplo, do exemplo apresentado pela própria Orlandi onde a expressão Nova República, utilizada por Tancredo Neves para definir o regime subseqüente ao regime militar, silencia a mesma ditadura, mas a partir de uma formação discursiva de dominação.

É, portanto, este espaço de silêncio, que atravessa as palavras e as constitui, que possibilita o movimento dos sentidos e permite que o mesmo enunciado signifique de modos tão diversos de um ano para outro. Não fosse o silêncio, observa Orlandi, e os sentidos seriam fixos: $O$ ato de nomear tem implicações ideológicas decisivas. A fala instaura espaços de silêncio. No silêncio, diz ela, o sentido é. E, podemos acrescentar: na linguagem, o sentido está. Está, como já vimos, a partir de determinadas condições de produção e de acordo com a formação discursiva do sujeito que fala. Está, portanto, sujeito a deslizamentos, a efeitos de sentido e a gestos de interpretação.

Acreditamos também que a afirmação de Orlandi de que no silêncio o sentido é significa que, no silêncio, o sentido não pode ser precisado, não pode ser colocado em palavras, na medida em que colocá-lo em palavras já significa uma interpretação, ou seja, já não é mais silêncio. Isto não impede, entretanto, que silêncio e linguagem compartilhem certos funcionamentos. Uma vez que dizer implica em não dizer e, sendo a linguagem determinada ideologicamente, o que é silenciado é tão da ordem do ideológico quanto o dito. Contudo, há um espaço de silêncio, o real, não alcançável pelas palavras, que permanece fora do ideológico. É nesta passagem, portanto, do sentido que é (silêncio) para o sentido que está (linguagem) que se dá a determinação ideológica.

Se, por um lado, não se pode analisar o sentido sem contemplar o funcionamento do silêncio na sua constituição, conforme diz Orlandi, por outro é importante observarmos que não se pode analisar o silêncio sem considerarmos sua relação imprescindível com a linguagem, uma vez que o silêncio só pode ser percebido em contraponto a ela, ou seja, só existe a partir da existência desta. Ou como diz Clarice Lispector: certamente, a linguagem um dia terá antecedido a posse do silêncio.

O silêncio, diz Eni Orlandi, é o real do discurso. Mas achamos importante destacar que, das diversas formas de silêncio, o silêncio fundante é que é o real do discurso, pois há outras formas de silêncio, ou melhor dito, de silenciamentos. Estes silêncios não são da ordem do real, mas são dizeres silenciados que podem desaparecer ou reaparecer, conforme a formação discursiva do sujeito ou as condições de produção 
do seu discurso. Há, porém, o silêncio fundante, aquele que é a própria condição do significar (Orlandi, 1997). Nas demais formas do silêncio, quando há uma remissão para o interdiscurso, não se trata de real.

A escritura de Clarice Lispector tem sido denominada, por diversos críticos, como a narração do indizível, devido a forte insistência da escritora em se aproximar daqueles espaços de silêncio, próprios de toda experiência humana, impossíveis de serem simbolizados. No caminho oposto ao interdito, que visa o apagamento de determinados sentidos, o silêncio, enquanto real do discurso, tal como trabalhado na obra de Clarice, abre os sentidos, mostrando que há modos de significação que a linguagem não alcança e que, por permanecerem abertos, na obra da escritora, se prestam a múltiplas interpretações, deixando ao leitor a possibilidade de buscar seus próprios sentidos.

Na contramão do trabalho da ideologia, que busca pela incessante repetição parafrástica criar a evidência do sentido, o silêncio cria espaços de reflexão e de deslizamentos de sentidos, mostrando que não há nem sentido único, nem literal. Neste sentido, a escritura de Clarice Lispector se revela um campus profícuo para a análise das relações entre silêncio, linguagem e ideologia, bem como da oposição existente entre silêncio e interdito, ou silêncio e silenciamento.

E é, ao fazer uma crítica da linguagem, através do trabalho do silêncio, que a escritura de Clarice Lispector se aproxima dos pressupostos teóricos da AD. Inerente a todo o funcionamento da linguagem e por isto mesmo fundante, o real do discurso tem, na arte, de modo geral, e na literatura, de modo específico, um espaço privilegiado para operar como uma crítica à ideologia, demonstrando a opacidade da linguagem e o modo como a sua suposta transparência é construída pelo silenciamento de muitos sentidos. Desenvolvendo-se como uma crítica à linguagem, a literatura de Clarice Lispector é espaço privilegiado para a análise do silêncio enquanto real do discurso e mantém uma forte interseção com a Análise do Discurso, uma vez em que esta se propõe a ser uma teoria crítica da linguagem.

Ao iniciar seu livro Uma aprendizagem ou o livro dos prazeres com uma vírgula, seguida de gerúndio (SDR 1) e, ao encerrá-lo com dois pontos (SDR 2), a escritora Clarice Lispector marca de forma extraordinária, na literatura, a presença do discursivo.

SDR1 - estando tão ocupada, viera das compras de casa que a empregada fizera às pressas porque cada vez mais matava serviço, embora só viesse para deixar almoço e jantar prontos, dera vários telefonemas tomando providências, inclusive um dificílimo para chamar o bombeiro de encanamentos de água, fora à cozinha para arrumar as compras e dispor na fruteira as maçãs que eram a sua melhor comida, embora não soubesse enfeitar uma fruteira, mas Ulisses acenara-lhe com a possibilidade futura de por exemplo embelezar uma fruteira (...) (LP, p.19-20)

SDR2 - - Meu amor, você não acredita no Deus porque nós erramos ao humanizá-lo. Nós O humanizamos porque não $\mathrm{O}$ entendemos, então não deu certo. Tenho certeza de que Ele não é humano. Mas embora não sendo humano, no entanto, Ele às vezes nos diviniza. Você pensa que -

- Eu penso, interrompeu o homem e sua voz estava lenta e abafada porque ele estava sofrendo de vida e de amor, eu penso o seguinte: (LP, p.182)

Tanto na SDR 1 que, sendo o início do romance, inicia com uma vírgula, como na SDR 2 final do mesmo romance - Uma aprendizagem ou o livro dos prazeres que termina com dois pontos, nós temos a presença do discursivo, seja pela presença de um dizer anterior (marcada pela vírgula na SDR1) como de um dizer posterior (marcado pelos dois pontos na SDR 2) que nos diz que o discurso não tem nem início nem fim. 
Clarice remete, assim, o leitor para o espaço do interdiscurso. Embora este espaço do interdiscurso seja um espaço indefinido, onde muitos sentidos podem ser acrescentados, fica marcado o fato de que todo dizer tem um outro dizer que o precede e todo dizer remete a um novo dizer. É interessante também observar que, ao deixar um espaço de silêncio antes da vírgula que inicia o romance e um espaço de silêncio que se segue ao ponto final que encerra o romance, Clarice mostra também que é o silêncio que funda a linguagem.

Solange Gallo, em Como apre(e) nder essa matéria? Análise discursiva do texto na escola, demonstra que, no processo de textualização do discurso que dá origem ao texto, o final, que permite a este texto se constituir como tal é um efeito, o efeito-fecho. É este efeito que estabelece, inclusive, a direção do sentido dada pelo sujeito-autor, ou seja, determinações de ordem ideológica presentes no texto. Nas seqüências discursivas que estamos analisando, nós percebemos como Clarice Lispector deixa evidente a textualização do discurso porque tanto o início - com uma vírgula - como o final com dois pontos - desfaz não só o efeito-fecho do texto como nos demonstra que também o início de um texto é um efeito: o efeito-início. Determinante na direção do sentido que este texto irá tomar, o efeito-início é o estabelecimento do corte que este texto realiza no contínuo discursivo, logo, das mobilizações que serão feitas a partir do interdiscurso.

Ao iniciar com uma vírgula e encerrar com dois pontos Uma aprendizagem ou o livro dos prazeres, Clarice Lispector escancara o processo de elaboração do texto, deixando em evidência que sua origem é discursiva e como tal não tem início, nem fim, mas que estes são um gesto de interpretação do sujeito-autor. Remetendo o leitor, por meio de uma pontuação inusitada, para o espaço intranqüilo do interdiscurso, deixa o texto em aberto de forma que ele é obrigado a buscar seus próprios sentidos para a sua compreensão. Desconstruindo a unidade textual, Clarice revela aquilo que a Análise do Discurso teoriza, a saber: que o discurso é um continuum: não tem início, nem fim; ( remete sempre a outros discursos (o já dito ou interdiscurso), constitutivo do seu dizer; e também aponta para um devir discursivo. Ou seja, nunca se diz tudo; há sempre um resto.

O resto é exatamente trabalho do silêncio, eixo central do funcionamento de toda linguagem, como bem aponta Orlandi. Trabalhando exatamente nos limites deste resto, que a Análise do Discurso detecta, Clarice Lispector leva a linguagem até as suas bordas, até aquilo que ela não alcança. Para nos levar ao ponto onde a experiência humana é inacessível à ordem do simbólico, Clarice promove uma ruptura constante com a normatização gramatical, exigindo para a análise do funcionamento do seu texto que se mobilize noções próprias da Análise do Discurso, uma vez que o estritamente linguiístico, ou a linearidade do texto, não dá conta dos sentidos que ali estão postos, ou expostos à interpretação.

Determinados historicamente e pelo contexto em que aparecem, tanto quanto a linguagem o silêncio tem diversas formas (ORLANDI,1997) e funcionamentos. Identificamos, no decorrer deste trabalho, três funcionamentos distintos do silêncio em Clarice Lispector:

\section{A REMISSÃO PARA O INTERDISCURSO, NUMA CRÍTICA AO DISCURSO HEGEMÔNICO}

SDR 3 - Tudo isso eu disse tão longamente por medo de ter prometido demais e dar apenas o simples e o pouco. Pois esta história é quase nada. O jeito é começar de repente assim como eu me lanço de repente na água gélida do mar, modo de enfrentar com uma coragem suicida o intenso frio. Vou agora começar pelo meio dizendo que - 
- que ela era incompetente. Incompetente para a vida. Faltava-lhe o jeito de se ajeitar. Só vagamente tomava conhecimento da espécie de ausência que tinha de si mesma. Se fosse criatura que se exprimisse diria: o mundo é fora de mim, eu sou fora de mim. (Vai ser difícil escrever esta história. Apesar de eu não ter nada a ver com a moça, terei que me escrever todo através dela por entre espantos meus. Os fatos são sonoros mas entre os fatos há um sussurro. É o sussurro o que me impressiona). (HE, p.24)

Nesta passagem de A hora da estrela, o narrador Rodrigo S. M. fala sobre as dificuldades de contar a história da nordestina Macabéa. Tem-se aí uma primeira ruptura com o discurso hegemônico, esta com a ordem do discurso narrativo, uma vez que o narrador anuncia que terá que contar a história como quem se lança repentinamente na água gelada do mar: pelo meio. A história inicia, então, pelo meio, marcado graficamente pelos travessões que interrompem a fala do narrador numa linha e, após o acréscimo de um espaço em branco até o meio da próxima linha, retoma, então, a fala do narrador com a história propriamente dita.

Num segundo momento, a ruptura com o discurso hegemônico se dá pela escolha da própria heroína da história: ela é incompetente, vale dizer, ela está exatamente na contramão daquilo que Chauí (2000) define como a ideologia dominante na sociedade contemporânea: a ideologia da competência. Mais adiante, ainda na SDR 3 que estamos analisando, o narrador interrompe seu discurso, agora por meio de parênteses, para falar sobre a própria função de escritor e sobre o fato de que o sujeitoautor, necessariamente, está presente em sua escritura: Apesar de eu não ter nada a ver com a moça, terei que me escrever todo através dela por entre espantos meus.

\section{REMISSÃO PARA PONTOS INDETERMINADOS DO INTERDISCURSO}

Os espaços de silêncio são preenchíveis pelo leitor. Clarice denuncia aí como se dá o processo de textualização do discurso.

SDR 4 - E agora - agora só me resta acender um cigarro e ir para casa. Meu Deus, só agora me lembrei que a gente morre. Mas - mas eu também?

Não esquecer que por enquanto é tempo de morangos.

Sim. (HE, p.87)

A SDR 4 é a seqüência final do romance $A$ hora da estrela. Após a morte de Macabéa, o narrador Rodrigo S.M. indaga-se sobre a própria morte, encerrando, em seguida, o romance, pelo sim, seguido de ponto final. Clarice, ao mesmo tempo, em que demonstra aí que o final é uma criação do próprio autor, ou seja, é um efeito-fecho, remete o leitor para algum ponto indefinido do interdiscurso a ser preenchido por ele. $\mathrm{O}$ sim pode remetê-lo, por exemplo, para a pergunta sobre a morte: Mas - mas eu também? Paralelamente a isto, entre a pergunta sobre a morte e o sim, há o enunciado: Não esquecer que por enquanto é tempo de morangos. Estas lacunas sintáticas, produzidas por Clarice, seguidamente, em seus textos, criam brancos semânticos, preenchíveis pelo leitor. Por fim, o Sim que finaliza o romance pode também remeter para um novo começo, através de uma remissão para o intertexto, uma vez que o próprio início do romance é: Tudo no mundo começou com um sim. Uma molécula disse sim a outra molécula e nasceu a vida. O que importa, portanto, é verificar que, no caso da SDR 4, o silêncio propicia a reverberação de muitos sentidos que serão preenchidos pelo leitor-autor da escritura de Clarice. 
REMISSÃO PARA O SILÊNCIO, ENQUANTO REAL DO DISCURSO, OU O INDIZÍVEL NO DIZER DE CLARICE

SDR 5 - - - - - - estou procurando, estou procurando. Estou tentando entender. Tentando dar a alguém o que vivi e não sei a quem, mas não quero ficar com o que vivi. Não sei o que fazer do que vivi, tenho medo dessa desorganização profunda. Não confio no que me aconteceu. Aconteceu-me alguma coisa que eu, pelo fato de não a saber como viver, vivi uma outra? A isso quereria chamar desorganização, e teria a segurança de me aventurar, porque saberia depois para onde voltar: para a organização anterior. A isso prefiro chamar desorganização pois não quero me confirmar no que vivi — na confirmação de mim eu perderia o mundo como eu o tinha, e sei que não tenho capacidade para outro. (PSGH, p. 9)

SDR 6 - O mundo independia de mim - esta era a confiança a que eu tinha chegado: o mundo independia de mim, e não estou entendendo o que estou dizendo: nunca! Nunca mais compreenderei o que eu disser. Pois como poderia eu dizer sem que a palavra mentisse por mim? Como poderei dizer senão timidamente assim: a vida se me é. A vida se me é, e eu não entendo o que digo. E então adoro - - - - - (PSGH, p.115)

As SDRs 5 e 6, respectivamente início e final do romance $A$ paixão segundo $G H$, são exemplares de tudo que temos desenvolvido até o momento sobre o silêncio em Clarice Lispector naquilo que tem sido o centro desta reflexão: o encontro da linguagem com o real do discurso em oposição ao silenciamento. Este encontro com o indizível, segundo Clarice, se dá exatamente no exercício da linguagem, ou seja, ao alcançarmos as fronteiras da linguagem, chegamos ao que não pode ser dito.

Do ponto de vista gramatical, o travessão é uma pausa rítmica que não quebra a continuidade do discurso, indicativa de que a frase ainda não foi concluída (ROCHA LIMA, 1972, p.422). Lispector faz aí, neste uso inusitado do travessão, aquilo que Barthes chama de crítica da linguagem (BARTHES, 1988). Mais, ao nos remeter, aparentemente, para o interdiscurso, ela nos lança, efetivamente, no silêncio, no real do discurso. Enquanto real do discurso, e só enquanto real do discurso, no silêncio, não há ideologia porque o ideológico é próprio do sujeito e o sujeito se constitui na e pela linguagem. É em função disto que o real, sendo o espaço próprio da movência do sujeito e do sentido, é também o espaço por excelência de transgressão da linguagem e de resistência à ideologia.

Neste sentido, o trabalho sobre o real é revolucionário por si só, pois é ali, digamos, que encontramos as bordas da linguagem e é, ali também, que encontramos o que do humano não pode ser simbolizado, que não está atravessado pela interpretação, e, portanto, não sofreu ainda determinação ideológica. Este trabalho é desenvolvido através da expansão dos espaços de silêncio constituintes das palavras e, ao contrário de ser uma manifestação exitosa da escrita é, exatamente, no fracasso da linguagem, como bem demonstrou Clarice Lispector, que encontramos o indizível. É ali, nas brechas da linguagem, onde nos deparamos com o silêncio fundante, tal como teorizado por Orlandi, que somos impelidos a um desacomodamento da nossa relação com a linguagem e, em conseqüência, com a nossa compreensão do mundo.

Ao colocar como eixo de sua escritura o indizível, Clarice se aproxima de vários pressupostos teóricos da $\mathrm{AD}$ como a descontinuidade do discurso, a fragmentação do sujeito, - sua constituição pela linguagem e, ao mesmo tempo, sua cisão pela própria natureza do simbólico - a movência dos sentidos, a ausência de um início e de um final discursivo, tudo isto tematizado não teoricamente, mas ficcionalmente, seja pela fala de seus personagens, ou de forma expressiva, pela singularidade de sua sintaxe. 
Numa crítica contundente e, ao mesmo tempo, sensível à ideologia, através de uma crítica à própria linguagem, lugar privilegiado de materialização desta, Clarice promove uma renovação da língua ao expandir os espaços de movência dos sentidos até ao ponto em que esta toca no real. Deste modo, ao invés de fechar os sentidos, movimento próprio do totalitarismo e dos meios de comunicação de massa, lança-os inteiramente em aberto para o leitor, exigindo a participação deste na sua constituição. Assume especial função, neste sentido, a aproximação com o real, local de desconcerto do sujeito continuamente vinculado a uma determinada rede discursiva. Dito de outro modo, é ao questionar a própria linguagem que Clarice leva o leitor à experiência de que ele é, enquanto sujeito, inevitavelmente cindido pelo simbólico e a encontrar-se com os pontos de sua experiência pessoal impossíveis de serem simbolizados, obrigando-o a uma transposição da realidade para o real.

Tomando como ponto de partida para as análises a pontuação como pista do silêncio no texto de Clarice, este estudo avançou no sentido de perceber que, embora o silêncio, costumeiramente, só tenha pistas e não marcas lingüísticas como diz Orlandi, no caso de nosso corpus, esta afirmação não se confirma, uma vez que a pontuação, como se verificou, funciona como marca discursiva do silêncio.

Trabalhando a pontuação na contramão de todo funcionamento lingüístico e gramatical, Lispector lança o leitor no leito do discurso e, ainda para além deste, para onde já não se encontram palavras. Assim, num encontro frutífero com a Análise do Discurso, Clarice expressa ficcionalmente o que esta teoriza, a saber, que não existe neutralidade na linguagem e que todo dizer é, por excelência, ideológico e vinculado a uma rede discursiva. Para escapar ao ideológico é imprescindível escapar ao universo das palavras. Esta crítica é feita, portanto, sobretudo a partir de um trabalho do silêncio (pontuacionalmente marcado) porque é no irromper do silêncio que a ilusão de transparência da linguagem é desconstruída.

É ao trabalhar o sentido como uma evidência no interior da Formação Discursiva com a qual o sujeito se identifica, diz Pêcheux, com base em Althusser, dando a impressão de um sentido literal, que a ideologia faz seu trabalho. É, portanto, através do silenciamento de determinados sentidos que cria a ilusão de outros como evidentes.

Escancarando o processo de textualização do discurso, Clarice não só leva o leitor a uma participação atuante no processo de produção do sentido como provoca um questionamento de sua relação com o mundo a partir de uma crítica ao discurso hegemônico que se dá por meio de uma crítica da linguagem.

Utilizando-se discursivamente da pontuação, promove a transgressão da língua a partir da transgressão de sua estrutura sintática. E faz, neste percurso, uma crítica à ideologia, obrigando o leitor a defrontar-se com o espaço único em que esta não opera, a saber, o silêncio fundante, o real do discurso. Na medida em que abre os sentidos em direções não determinadas, desacomodando o sujeito de encontrar o sentido ali onde ele era esperado, Clarice faz uma crítica à ideologia, através de uma crítica da linguagem , lugar de sua materialização.

A partir daí, pode-se pensar que o silêncio em Clarice trabalha no sentido contrário ao do silenciamento. Enquanto o silenciamento busca a evidência de um sentido único num trabalho da ideologia, Clarice trabalha, pelo silêncio, com a reverberação dos sentidos em muitas direções, até ao ponto do sentido não traduzível pelas palavras, mostrando que a linguagem sempre nos limita numa rede de já dito e que a experiência humana ultrapassa estes limites.

Clarice se opõe à ideologia, mergulhando no inconsciente à procura da fonte da palavra e não encontra linguagem porque a fonte da palavra é o silêncio. Mergulhado na rede do simbólico, o sujeito é, inextricavelmente, determinado pela ideologia, mas resta 
uma região a ele desconhecida, o inconsciente. A impossibilidade de dizer está também ligada às dificuldades de se romper a estrutura da língua. Por isto o trabalho de Clarice na/sobre a linguagem.

Simbolizar é, assim, um ato político e ideológico por excelência. É o ato que cinde o sujeito. Existe, sim, um espaço do sujeito fora do ideológico, mas este espaço é silêncio. É algo fora do alcance do sujeito. Algo que não the é permitido simbolizar. Este espaço determina a movência do sujeito e do sentido, uma determinação já não de ordem ideológica, mas inconsciente. Mas quando entra no simbólico o sujeito é determinado ideologicamente, por vezes, até tentando velar os sentidos que lhe são vislumbrados no silêncio. Estes sentidos silenciados vão aparecer nos lapsos, nos equívocos, nos atos falhos, lugares não só de manifestação do inconsciente, mas do trabalho da ideologia.

Como tudo que é determinado historicamente, a ideologia também sofre transformação através do tempo, de modo que as manifestações de sua operação se modificam. Ao deslocar a concepção marxista de ideologia como ocultação para o âmbito do discurso, Michel Pêcheux diz que o ideológico se manifesta como um efeito de evidência do sujeito e do sentido. Este trabalho da ideologia só é possível a partir do silêncio, pois é dando a impressão da existência de um sentido literal, ou único, ou seja, é pelo efeito de apagamento não só de outros sentidos, mas também das próprias condições de produção do sentido que a ideologia faz seu trabalho: sem o silêncio isto não seria possível.

Orlandi (1997, p.71) destaca que há, no social, uma "ideologia da comunicação", que se traduz pela urgência do dizer e pela necessidade de, dizendo muito, não deixar espaços vazios, buscando promover, assim, um ideal de transparência, do sentido. Esta ideologia da comunicação funciona de tal modo que, na opinião de González, o silêncio, na sociedade moderna, é um inimigo do poder:

Algo hay, sin embargo, de patológico em la actitud de la sociedade moderna frente al silencio. Parece com si la sociedade tecnológica hubiera hecho de él el enemigo que hay que confinar y suprimir. Nuestros espacios público y privado se vem invadidos totalmente por el ruído, el sonido y la palabra. (...)La civilización tecnológica puede entenderse así como uma exorcización del silencio, el la cual se manifesta su instinto de domínio y poder. Hay que mantener distraída y ocupada a la gente. (González, 1992)

Clarice se opõe claramente a esta ideologia da comunicação. Buscando através da linguagem aquilo que ela não pode alcançar, Clarice nos dá o silêncio, pois, como destaca Olga de Sá, concluindo que é impossível que a palavra diga o ser, ela vislumbra o silêncio como única possibilidade de alcançar o indizível. (Sá, 1979, p.151).

Ao trabalhar os espaços de silêncio na linguagem, Clarice desconstrói o processo de constituição do texto, denunciando que sua origem é discursiva. Ao discursivizar o texto, Clarice promove a única possibilidade de transgressão da língua que é a transgressão de sua própria estrutura interna, a sintaxe. Rompe, assim, com aquilo que Barthes define como o poder intimidador da estrutura lingüística, desfazendo a evidência do sentido e demonstrando que todo dizer está imerso num contínuo discursivo.

Escancarando o processo de textualização do discurso, Clarice não só leva o leitor a uma participação atuante no processo de produção do sentido, como o leva, através do silêncio, a regiões suas desconhecidas, provocando com isto um questionamento de sua relação com o mundo a partir de uma crítica ao discurso hegemônico que se dá por meio de uma crítica da linguagem.

Utilizando-se discursivamente da pontuação, promove a transgressão da língua a partir da transgressão de sua estrutura sintática. E faz, neste percurso, uma crítica à ideologia, obrigando o leitor a defrontar-se com o espaço único em que esta não opera, a saber, o silêncio fundante, o real do discurso. 


\section{BIBLIOGRAFIA}

BARTHES, R. Rumor da Língua. São Paulo, Brasiliense, 1988.

CHAUÍ, M. Entrevista. Revista Cult, n 35, junho de 2000.

GALLO, S. Como apre(e)nder essa matéria? Análise discursiva do texto na escola. Tese de doutorado, Campinas, IEL/UNICAMP, 1994.

GONZÁLEZ, J.R. El significado del silencio y el silencio del significado. In: Del Pino, C.C.(Org.). El silencio. Madrid, Alianza Editorial, 1992.

ORLANDI, E. A linguagem e seu funcionamento - as formas do discurso. Campinas, Pontes, 1996.

. As formas do silêncio. Campinas, Ed.da UNICAMP, 1997.

PÊCHEUX, M. Semântica e Discurso. Campinas, Pontes, 1995.

SÁ, O. A escritura de Clarice Lispector. Petrópolis, Vozes, 2000.

Obras de Clarice Lispector:

HE - A hora da Estrela. Rio de Janeiro, Rocco, 1998.

LP - Uma aprendizagem ou o livro dos prazeres. Rio de Janeiro, Francisco Alves, 1990.

PSGH — A paixão segundo GH. Ed. In: Nunes, B. (coord.). Florianópolis, UFSC, 1988. 